\title{
Engineering Student Retention and Attrition Literature Review
}

\author{
Elizabeth A. Kuley, Sean Maw, and Terry Fonstad \\ University of Saskatchewan \\ liz.kuley@usask.ca
}

\begin{abstract}
The University of Saskatchewan, similar to many engineering colleges, would like to improve student retention. With that in mind, a literature review was undertaken to summarize current peer reviewed literature related to engineering student retention and attrition in an attempt to better understand the potential structural causes, processes, and student characteristics that may contribute to student success or attrition. Through a systematic search of several major databases using the keywords "engineering and attrition or retention," and after narrowing the scope to peer reviewed articles written between 2005 and the present, each article's abstract was read and evaluated. Forty-five papers were deemed to be highly relevant, and were thus included in the literature review. Preliminary trends that have emerged in this review are: the potential causes of high attrition rates in engineering schools, various methods that have been used to determine the causes of attrition, interventions that have been implemented and stories of their success/failure, and attributes that have been found to correlate with student attrition or success. This paper is an attempt to organize this body of research into a singular source that can be referenced by engineering educators or researchers who wish to increase student retention and improve the educational experience of their students.
\end{abstract}

Keywords: first year, retention, attrition, engineering, literature review

\section{INTRODUCTION}

Many engineering colleges in North America have made retention a priority in their programs, especially for first year students, in order to lessen the financial and societal cost of student attrition [16]. It is also clear that in the near future we will require more engineering graduates to meet industry demand, and these engineers will require specific traits in order to thrive in a rapidly changing and advancing economy [30]. Engineers can be viewed as a unique group of students [48].

Despite this push for better retention and a significantly higher number of graduating engineers, there is very little published research that looks at the issue comprehensively, and that accounts for all of the potential factors that may go in to a student's decision to stay or leave engineering majors. There are especially few research papers focused on engineering students specifically, although engineering student attrition has been found to have different causes than non-engineering student attrition [48]. Attrition in engineering schools is a highly complex problem that requires a collaborative approach (between students, colleges and instructors, using different methodologies) to fully understand and solve. The first step in understanding and solving this problem and the purpose of this paper is to compile and synthesize current literature into a singular, easy to digest source.

The following diagram shows the process by which appropriate literature was identified:

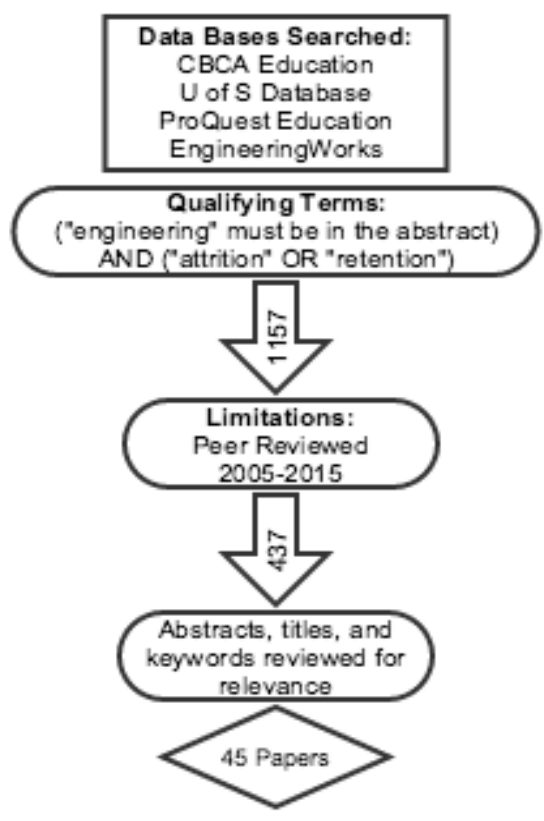

Fig. 1. Paper Selection Process.

After reading and summarizing 45 papers, several themes emerged that can be organized into three distinct categories or "levels": College Level Factors, Instructor 
Level Factors, and Student Level Factors. These category headings were inspired by Robert Marzano, who described the three levels of factors that influence the effectiveness of schools and student achievement: school level factors, teacher level factors, and student level factors [33], which were written with elementary and high-school education in mind. Though not intended for higher education, these levels (slightly altered) are a convenient and holistic way to discuss the factors that affect engineering student attrition.

\section{COLLEGE/FACULTY LEVEL FACTORS}

\subsection{Institutional Climate}

Institutional climate is made up of many intangible factors such as how welcome the students feel, faculty engagement, cultural atmosphere, and social environment. It can also include research involvement, the existence of the "weed out" culture that engineering is known for, and the academic achievements of students within the institution.

The importance of institutional climate on student retention and satisfaction cannot be overemphasized, especially for female and minority students [39], which will be further discussed in Student Level Factors. Though student level factors play a role in student attrition, college level factors are the underlying mechanisms that can either exacerbate or supersede student level factors. For instance, engineering schools that don't emphasize work life balance for engineering as a career will retain fewer students [29]. So too will institutions that perpetuate the concept of a "weed out" culture [46]. In order to retain students, it is important to take into account student demographics and motivations that have changed; young engineers (and students) value flexible and supportive work environments [30] and will look for educational experiences with this in mind.

Students who stay in engineering colleges are not necessarily the "cream of the crop" as weed-out culture suggests, but rather they are a certain type of person, most often a very resilient person who has a high motivation to learn and is less affected by situational/environmental factors than their peers [31]. The students who drop out of engineering are generally found to be academically similar to their peers who stay in engineering [40]. The students who leave do however, report more negative feelings towards factors such as faculty-student relationships, and feel as though the college does not want them to succeed. These feelings have consistently been found to correlate with attrition from engineering colleges [9] [49].

\subsection{Curriculum}

Though students' first year is the most critical experience to their choice to leave engineering or not, many researchers including Froyd and Ohland [13] suggest that first year engineering curricula are largely theoretically based and stagnant, lacking context-oriented approaches and creating negative perceptions of engineering for students [26] [32], which in turn leads to higher attrition rates within the college setting for millennial students who crave context and flexibility [30]. Students value real-world examples and feel that they enhance the quality of their education [43]. Without these real-world connections students can lose interest in the profession before they even fully understand what it is that engineers do or how diverse the profession is.

The engineering profession in Canada is changing (and has changed) [30] and students will require interdisciplinary competencies in order to thrive [13]. Students want to learn what engineering is and feel let down by the overloaded curriculum that lacks relevance to current engineering practice [13] [40] [43]. Also, due to the wide range of backgrounds of students coming into engineering schools, there is a clear knowledge gap between some students' prior knowledge based on where they attended high school [22] [28]. Students that have less mathematics preparation are more likely to leave engineering, and will require more assistance than their peers in order to persist [2] [28]. The varying backgrounds and academic preparation of students affect individual achievement and thus affect attrition [27]. This is a predictor that is uniquely found in engineering student attrition [50], and is in no way an indicator of students' academic capability, but rather, their preparation (which is largely out of their control).

Intentionally redesigned curriculum that incorporates a more respectful atmosphere, supplemental material for underprepared groups of students, and more flexibility will improve outcomes and retention in all students [14] [29] [36] [45], but especially in the minority groups of interest to many engineering colleges in Canada. Engineering curricula combined with institutional climate is arguably the most significant predictor of student attrition, as these factors contribute to and interact with every other factor.

\subsection{Mentorship}

There have been many engineering schools that have implemented mentorship programs either with industry, upper year engineering students, or faculty; some of these efforts have been very successful in increasing retention [5] [25] [44], and some have not [35] (though every program documented does increase student satisfaction overall). Mentorship programs seem to be very successful with minority demographics in engineering schools [5] 
[25]. Minority groups in engineering (including female students, aboriginal students, and visible minority students) are lacking role models and generally have lower technical self-efficacy (strength of a student's belief in their ability to complete technical tasks and get good grades) than the dominant demographic [28]; mentorship programs are one way to give these students a support system and sense that they belong there, in order to retain a larger number of a very small proportion of the engineering student population.

Also important to student retention/attrition is a student's access to role models. Students are more likely to choose and continue in engineering when they themselves know an engineer [10], and are more likely to complete their degrees when they have parents that have a university degree [22].

\subsection{Peer Influence and Sense of Belonging}

Peer mentorship has a positive effect on students' drive to continue in engineering [5]. Intuitively this makes sense; if a student has someone to look up to and guide him or her through the program, they are more likely to succeed. Also, if they have friends in the program, they are more likely to feel that they "fit in" and belong there. Allendoerfer et al. assert that, "providing students with opportunities to belong provides the most return on investment for engagement in academic endeavors" [1].

It's been shown that students who report having a lower sense of belonging tend to leave engineering colleges more often [32]. A poor sense of belonging among students is also a symptom of poor institutional climate. If engineering students cannot foster a sense of belonging with their peers, they will find it difficult to feel that the program is worth the strenuous effort to complete [11]. This intangible but very real sense of community and belonging to that community is another one of the most significant factors that affect student attrition.

\section{STUDENT LEVEL FACTORS}

\subsection{Academic Achievement}

Given that many engineering schools in Canada accept students based on their entrance averages, it makes sense that higher academic achievement in high school is correlated with higher retention rates [8] [37] [48]. Mendez et al. found that cumulative GPA is most highly associated with engineering persistence or nonpersistence [34]. Although academic achievement is correlated with attrition, it cannot be considered a causal relationship.

There are also specific measures from a student's high school academic record that have been found to correlate with attrition such as high school average and SAT math score [8] [12] [37] [48]. Also, good study and time management skills that students have from high school have been found to correlate with student success and retention [4].

\subsection{Learning Style}

There is certainly an "engineering culture" that is important to foster in students [15], but under the umbrella of "engineer," there are many different types of people that must be accounted for in order to increase retention. Engineering students are a diverse group of individuals who have vastly differing backgrounds, personalities, and skills [30]. Given the highly variable nature of engineering as a profession, students with differing personalities and learning styles all have the ability to succeed in engineering as a profession [4] [29]; it is not only desirable that diversity be accommodated, but it is desirable for employers and the profession as a whole [30].

Though the student demographic in most engineering schools is diverse and there are several different personalities and learning styles, many engineering courses are being taught for a distinctive type of individual [4] [51]. Bernold et al. suggest that the types of learners and thinkers that engineering "weeds out" are exactly the types of learners and thinkers that industry is asking for in graduates [4]. Engineering schools can lower attrition rates by addressing these differing learning styles and ways of thinking [4].

\subsection{Intrinsic Motivation and Attitude}

There are some students who are so motivated to become engineers that their commitment to their education is virtually untouchable; poor faculty relationships, an over-loaded and dry curriculum, lack of community in the college, and even failure will not deter them from their goal [12]. These students have a strong belief that engineering is the right career for them, though they may still hold negative views of engineering education or their college [6]. These students tend to have certain types of learning styles and personality types, such as "proactive personality" [6] [31].

Students who have this intrinsic motivation are more likely to have role models who show them what an engineering career will look like for them, and thus are more willing to persist through hardships in engineering education (or perceived hardships). However, there are many more students who are struggling, but persist in their degree and hold damaging negative views of the college and faculty; these students are more likely to feel that their professors intentionally make courses more difficult than necessary to weed out students, and are more likely to leave engineering [46]. 


\subsection{Self-Efficacy}

Lower self-efficacy is correlated with higher attrition rates, especially in female students [35]; however, students with lower self-efficacy do not necessarily differ from their peers in academic ability [6] [10]. Students' self-efficacy and self-confidence can be affected by faculty relationships, institutional climate, and teaching methodology [49]; and it is essential for student satisfaction [19]. Self-efficacy is also one of the simplest factors to affect externally. If low self-confidence can be identified early on in a student's degree, interventions can be made to modify their self-perception before attrition occurs [28].

\subsection{Demographics}

3.5.1 Gender. Whether female students have a higher or lower attrition rate seems to depend on the institution, as findings in this area are inconsistent. However, female students' reasons for leaving the college differ [18] [28], and they tend to leave at a different point in their educational path than male students [37]. Male students who leave the college tend to be less prepared than their male counterparts who continue in the program whereas female students who leave are not significantly different than their counterparts who stay in the program [18]. Female students also tend to be more committed to their majors.

Female students' self-efficacy beliefs are more affected by external characteristics such as institutional climate and faculty, which contribute to student attrition. Ohland et al. suggests that female students are also more affected by curriculum deficits; and that retention is improved when engineering schools emphasize problem solving, technical writing, teamwork, entrepreneurship, and business management skills. Female students also thrive when given the context of problems rather than idealized abstract problems that tend to populate the first year engineering curriculum [13].

Females, when other variables are controlled for, are more likely to graduate than males [8], but are more negatively susceptible than male students to comparisons with their peers [23] [17], and more susceptible to stereotype threat [3]. Female students tend to have lower self-efficacy [7] [24], which in turn contributes to female student attrition. In contrast, female students that continue in their programs have high self-efficacy and identify with the engineering persona [7], making institutional climate and self-efficacy of particular concern for the retention of female students, but important for all students regardless.

The perceived existence of problems within the engineering profession ("chilly" workplace environments) and professors who view students as "numbers, not names," etc. also contribute to student dissatisfaction and attrition for both male and female students [17]. Stereotypes that exist about engineers, the engineering profession, and engineering education are harming recruitment and retention efforts disproportionally for female students. However, female students that enter into the college tend to be very committed, having known that they were entering a non-traditional field [38].

3.5.2 Race. Caucasian students tend to have higher attrition rates than Non-Caucasian students, though NonCaucasian students are at the highest risk for leaving later on in their degree [37]. Interestingly, it has been shown that while improving institutional climate can create gender parity, it does not affect racial disparity in engineering colleges [39]. Racial disparity requires more sensitivity by engineering colleges to data driven teaching methodologies that are not only required to move engineering education forward with technology and societal priorities, but for improved minority group outcomes [41] [42].

\section{INSTRUCTOR LEVEL FACTORS}

Faculty can have a profound effect on student outcomes, including academic performance and sense of belonging [32]. If professors take the time to promote a welcoming environment and move away from verbalizing the "survival of the fittest" attitude, it will promote success in their students and reduce attrition. Faculty who are distant and perceived as unwelcoming to students lower self-efficacy in students as well as their academic achievement overall, and make them more likely to leave the college altogether [49].

It is important that engineering faculty understand their role in student attrition, as it is important, and perhaps more significant than previously accepted [9] [21] [49]. Conversely, if faculty provide a welcoming environment, are actively involved in student achievement, and provide professional role models, students are more likely to feel that engineering is "for them" [50].

Faculty can and should foster student engagement if a college is to reduce attrition rates and improve student satisfaction, but it is critical to understand how students and faculty differ in their understanding of the phrase "student engagement." Engineering faculty tend to think of student engagement as resting with students. However, students feel that engagement comes from faculty enthusiasm and willingness to give time outside of class [20]. Student engagement can be thought of as both a process and an outcome, resting with both faculty members and students [20]; however, challenges engaging faculty with research results may need to be overcome [47] in order to promote student success and retention. 


\section{DISCUSSION AND CONCLUSIONS}

This paper distilled recent literature in an attempt to understand the mechanisms that cause attrition in engineering students, as well as indicators that may exist to identify students who are more at risk for attrition. While this paper is focused on "the problem," it should be stated that this problem is not unsolvable. There are proven interventions that can increase retention by addressing any of these key issues, or by understanding the whole picture i.e. how each level interacts with one another, in order to implement comprehensive programming.

While all of the factors above have been shown to affect the retention and attrition of engineering students, it is their complex interactions that cause a student to leave engineering. It should be noted that the impact of the institution itself (curriculum, support systems in place, college climate, etc.) supersedes the effect that demographics or student perceptions may have. High attrition rates are not as much about individual students, as they are about the institutions that they feel they do or do not belong to.

There seems to be a pervasive idea that engineering is only "right" for a certain type of person. However, it is clear that engineering students do not all have the same type of personality, learning style, motivations, or background [6] [31] [46]. The way that some engineering classes are currently taught is not effectively engaging engineering students as a whole, but rather a certain type of student, leading to higher than necessary attrition rates, and the loss of potentially very good engineers.

\section{Acknowledgements}

The authors would like to thank The Gwenna Moss Centre for Teaching Effectiveness at the University of Saskatchewan for financially backing this project and supporting The College of Engineering in its efforts to understand student attrition.

\section{References}

[1] Nanette Allendoerfer, Cheryl; Wilson, Denise; Bates, Rebecca; Crawford, Joy; Jones, Diane; Floyd-Smith, Tamara; Plett, Melani; Scott, Elaine; Veilleux, "Strategic Pathways for Success: The Influence of Outside Community on Academic Engagement - ProQuest," Journal of Engineering Education, vol. 101, no. 3, pp. 512-538, 2012.

[2] Sarah Bamforth, Adam Crawford, Anthony Croft, and Carol Robinson, "A pre-sessional course: retaining engineering students through mathematical and transferable skills support - ProQuest," International
Journal of Electrical Engineering Education, vol. 42, no. 1, pp. 79-87, 2005.

[3] Maya A Beasley and Mary J Fischer, "Why they leave: the impact of stereotype threat on the attrition of women and minorities from science, math and engineering majors," Social Psychology of Education : An International Journal, vol. 15, no. 4, pp. 427-448, Dec. 2012.

[4] Leonhard E. Bernold, Joni E. Spurlin, and Chris M. Anson, "Understanding Our Students : A LongitudinalStudy of Success and Failure in Engineering with Implications for Increased Retention," Journal of Engineering Education, vol. 96, no. 3, pp. 263-274, Jul. 2007.

[5] Dan Budny, Cheryl A Paul, and Beth Bateman Newborg, "Impact of Peer Mentoring on Freshmen Engineering Students," Journal of STEM Education : Innovations and Research, vol. 11, no. 5/6, pp. 9-24, 2010.

[6] Joan Burtner, "The Use of Discriminant Analysis to Investigate the Influence of Non-Cognitive Factors on Engineering School Persistence," Journal of Engineering Education, vol. 94, no. 3, p. 335, 2005.

[7] Kathleen Buse, Diana Bilimoria, and Sheri Perelli, "Why they stay: women persisting in US engineering careers," Career Development International, vol. 18, no. 2, pp. 139-154, 2013.

[8] Justin Chimka, Teri Reed-Rhoads, and Kash Barker, "Proportional Hazards Models of Graduation," Journal of College Student Retention: Research, Theory and Practice, vol. 9, no. 2, pp. 221-232, Jan. 2007.

[9] Barbara Christe, "The Importance of Faculty-Student Connections in STEM Disciplines: A Literature Review," Journal of STEM Education : Innovations and Research, vol. 14, no. 3, pp. 22-26, 2013.

[10] Ozgur Eris, Debbie Chachra, Helen L Chen, Sheri Sheppard, Larry Ludlow, Camelia Rosca, Tori Bailey, and George Toye, "Outcomes of a Longitudinal Administration of the Persistence in Engineering Survey," Journal of Engineering Education, vol. 99, no. 4, pp. 371395, Oct. 2010.

[11] Cynthia E. Foor, Susan E. Walden, and Deborah a. Trytten, " II Wish that I Belonged More in this Whole Engineering Group:' Achieving Individual Diversity," Journal of Engineering Education, vol. 96, no. 2, pp. 103 115, Apr. 2007.

[12] Brian F. French, Jason C. Immekus, and William C. Oakes, "An Examination of Indicators of Engineering Students' Success and Persistence," Journal of 
Engineering Education, vol. 94, no. 4, pp. 419-425, Oct. 2005.

[13] J E Froyd and M W Ohland, "Integrated engineering curricula," Journal of Engineering Education, vol. 94, no. 1, pp. 147-164, 2005.

[14] T Carter Gilmer, "An Understanding of the Improved Grades, Retention and Graduation Rates of STEM Majors at the Academic Investment in Math and Science (AIMS) Program of Bowling Green State University (BGSU)," Journal of STEM Education: Innovations and Research, vol. 8, no. 1/2, pp. 11-21, 2007.

[15] Elizabeth Godfrey and Lesley Parker, "Mapping the Cultural Landscape in Engineering Education," Journal of Engineering Education, vol. 99, no. 1, p. 5, 2010.

[16] Paul J. Grayson and Kyle. Grayson, "Research on Retention and Attrition," Millennium Scholarship Foundation, Montreal, Quebec, 2003.

[17] Harriet Hartman and Moshe Hartman, "How Undergraduate Engineering Students Perceive Women's (and Men's) Problems in Science, Math and Engineering," Sex Roles, vol. 58, no. 3-4, pp. 251-265, Oct. 2007.

[18] Harriet Hartman and Moshe Hartman, "Leaving Engineering: Lessons from Rowan University's College of Engineering," Journal of Engineering Education, vol. 95, no. 1, p. 49, 2006.

[19] Nancy N Heilbronner, "Stepping Onto the STEM Pathway: Factors Affecting Talented Students' Declaration of STEM Majors in College," Journal for the Education of the Gifted, vol. 34, no. 6, pp. 876-899, Dec. 2011.

[20] Rachelle S. Heller, Cheryl Beil, Kim Dam, and Belinda Haerum, "Student and Faculty Perceptions of Engagement in Engineering," Journal of Engineering Education, vol. 99, no. 3, pp. 253-261, Jul. 2010.

[21] Barbara S.S. Hong and Peter J. Shull, “A Retrospective Study of the Impact Faculty Dispositions Have on Undergraduate Engineering Students," College Student Journal, 2010.

[22] Nora Honken and Patricia A S Ralston, "Freshman Engineering Retention: A Holistic Look," Journal of STEM Education : Innovations and Research, vol. 14, no. 2, pp. 29-37, 2013.

[23] Mica Hutchison-Green, Deborah K Follman, and George M Bodner, "Providing a Voice : Qualitative Investigation of the Impact of a First-Year Engineering Experience on Students' Self-Efficacy Beliefs," Journal of Engineering Education, vol. 97, no. 2, pp. 177-190, 2008.
[24] Mica Hutchison, Deborah K. Follman, Melissa Sumpter, and George M. Bodner, "Factors Influencing the SelfEfficacy Beliefs of First-Year Engineering Students," Journal of Engineering Education, vol. 95, no. 1, pp. 3947, Jan. 2006.

[25] Kimberly D Kendricks, K V Nedunuri, and Anthony R Arment, "Minority Student Perceptions of the Impact of Mentoring to Enhance Academic Performance in STEM Disciplines," Journal of STEM Education : Innovations and Research, vol. 14, no. 2, pp. 38-46, 2013.

[26] Deborah Kilgore, Cynthia J. Atman, Ken Yasuhara, Theresa J. Barker, and Andrew Morozov, "Considering Context: A Study of First-Year Engineering Students," Journal of Engineering Education, vol. 96, no. 4, pp. 321334, Oct. 2007.

[27] Kathleen Koenig, Melissa Schen, Michael Edwards, and Lei Bao, "Addressing STEM Retention Through a Scientific Thought and Methods Course," Journal of College Science Teaching, vol. 41, no. 4, pp. 23-29, 2012.

[28] Qing Li, Hariharan Swaminathan, and Jiong Tang, "Development of a Classification System for Engineering Student Characteristics Affecting College Enrolment and Retention" Journal of Engineering Education, vol. 98, no. 4, pp. 361-376, 2009.

[29] Elizabeth Litzler and Jacob Young, "Understanding the Risk of Attrition in Undergraduate Engineering : Results from the Project to Assess Climate in Engineering," Journal of Engineering Education, vol. 101, no. 2, p. 319, 2012.

[30] Georges Lozano, "Engineering Profession Environmental Scan,” Engineers Canada Reports 2015.

[31] Debra A Major, Jonathan M Holland, and Kurt L Oborn, "The Influence of Proactive Personality and Coping on Commitment to STEM Majors," The Career Development Quarterly, vol. 60, no. 1, pp. 16-24, Mar. 2012.

[32] Rose M. Marra, Kelly A. Rodgers, Demei Shen, and Barbara Bogue, "Leaving Engineering : A Multi-Year Single Institution Study," Journal of Engineering Education, vol. 101, no. 1, pp 6-27, Jan. 2012.

[33] Robert J. Marzano, What Works in Schools: Translating Research into Action. Alexandria, VA: Association for Supervision \& Curriculum Development, 2003.

[34] Guillermo Mendez, Trent D. Buskirk, Sharon Lohr, and Susan Haag, "Factors Associated With Persistence in Science and Engineering Majors: An Exploratory Study Using Classification Trees and Random Forests," Journal of Engineering Education, vol. 97, no. 1, pp. 57-70, 2008. 
[35] Kerry L. Meyers, Stephen E. Silliman, Natalie L. Gedde, and Matthew W. Ohland, "A Comparison of Engineering Students' Reflections on Their First-Year Experiences," Journal of Engineering Education, vol. 99, no. 2, pp. 169178, Apr. 2010.

[36] Ivana Milanovic, Tom A Eppes, Janice Girouard, and Lee Townsend, "Retention-Oriented Curricular Design," Journal of College Teaching and Learning, vol. 7, no. 11, pp. 41-46, 2010.

[37] Youngkyoung Min, Guili Zhang, Russell A Long, Timothy J Anderson, and Matthew W Ohland, "Nonparametric Survival Analysis of the Loss Rate of Undergraduate Engineering Students," Journal of Engineering Education, vol. 100, no. 2, pp. 349-373, Apr. 2011.

[38] Frances Montgomery Haemmerlie and L Montgomery, Robert, "Gender Differences in the Academic Performance and Retention of Undergraduate Engineering Majors," College Student Journal, vol. 46, no. 1, pp. 4145, Mar. 2012.

[39] Matthew W. Ohland, Catherine E. Brawner, Michelle M. Camacho, Richard a. Layton, Russell a. Long, Susan M. Lord, and Mara H. Wasburn, "Race, Gender, and Measures of Success in Engineering Education," Journal of Engineering Education, vol. 100, no. 2, pp. 225-252, Apr. 2011.

[40] Matthew W. Ohland, Sheri D. Sheppard, Gary Lichtenstein, Ozgur Eris, Debbie Chachra, and Richard a. Layton, "Persistence, Engagement, and Migration in Engineering Programs," Journal of Engineering Education, vol. 97, no. 3, pp. 259-278, Jul. 2008.

[41] Maria Ong, Carol Wright, Lorelle L Espinosa, and Gary Orfield, "Inside the double bind: a synthesis of empirical research on undergraduate and graduate women of color in science, technology, engineering, and mathematics," Harvard Educational Review, vol. 81, no. 2, pp. 172-209, 2011.

[42] Robert T Palmer, Dina C Maramba, and Elon T II Dancy, "A Qualitative Investigation of Factors Promoting the Retention and Persistence of Students of Color in STEM,"
Journal of Negro Education, vol. 80, no. 4, pp. 491-504, 2011.

[43] Cristina Pomales-Garcia and Yili Liu, "Excellence in Engineering Education: Views of Undergraduate Engineering Students," Journal of Engineering Education, vol. 96 , no. 3, p. 253, 2007.

[44] Cara J. Poor and Shane Brown, "Increasing Retention of Women in Engineering at WSU," College Student Journal, pp. 421-429, 2011.

[45] Diane T. Rover, "The Academic Bookshelf: Inclusive Practices," Journal of Engineering Education, vol. 94, no. 3, pp. 349-350, Jul. 2005.

[46] Radhika Suresh, "The Relationship between Barrier Courses and Persistence in Engineering," Journal of College Student Retention, vol. 8, no. 2, pp. 215-239, 2007.

[47] Cindy P. Veenstra, Eric L. Dey, and Gary D. Herrin, "Is Modeling of Freshman Engineering Success Different from Modeling of Non-Engineering Success?" Journal of Engineering Education, vol. 97, no. 4, pp. 467-479, Oct. 2008 .

[49] Christina M Vogt, "Faculty as a Critical Juncture in Student Retention and Performance in Engineering Programs," Journal of Engineering Education, vol. 97, no. 1, pp. 27-36, Jan. 2008.

[50] Susan E. Walden and Cindy Foor, "'What's to keep you from dropping out?' Student Immigration into and within Engineering," Journal of Engineering Education, vol. 97, no. 2, pp. 191-205, Apr. 2008.

[51] Jessica Watkins and Eric Mazur, "Retaining Students in Science, Technology, Engineering, and Mathematics (STEM) Majors," Journal of College Science Teaching, vol. 42, no. 5, pp. 36-41, 2013. 